\title{
Guiding MF waves from the Earth's surface into space
}

\author{
D. V. Blagoveshchensky ${ }^{1}$, K. A. Dobroselsky ${ }^{1}$, O. A. Maltseva ${ }^{2}$ \\ ${ }^{1}$ State Academy of Aerospace Instrumentation, 67 Bolshaya Morskaya Str., St. Petersburg, 190000, Russia (nataly @ geophys. spb. su) \\ ${ }^{2}$ Institute of Physics, Stachky Str. 194, Rostov-on-Don, 344104, Russia (moa @ riphys. rnd. su)
}

Received: 22 May 1996 / Accepted: 11 September 1996

\begin{abstract}
The insufficiently known phenomenon of MFwave propagation from the Earth's surface through the magnetosphere (guiding) to the conjugate hemisphere and back to the transmitter has been experimentally studied. Computer modelling fulfilled on the basis of ray tracing showed that guiding was possible only from area of the main ionospheric trough. The effect of MF guiding is most useful for the diagnostics of the plasmapause, poleward edge of the trough, the diffuse precipitation boundary and so on.
\end{abstract}

\section{Introduction}

Wave ducting is a very important mechanism of propagation which has been extensively studied up to now in different frequency bands (Calvert, 1995). Magnetospheric ducting of MF waves is least investigated. There were ionospheric observations by means of topside ionosondes (Muldrew, 1963), but interhemispheric MF echoes were found only by Ellis and Goldstone (1988) for quiet conditions.

In this paper results of MF observations at St. Petersburg's station $(L=3.2)$ are discussed for magnetically disturbed conditions. It is shown that these results can be explained by wave propagation in the channel being formed by the trough and plasmapause. This interpretation allows to predict locations of the trough and plasmapause by means of MF-echo observations.

\section{Observations}

Experiments at St. Petersburg have discovered echo signals (frequency $1.8 \mathrm{MHz}$ ) with the average delay $\tau=0.29 \mathrm{~s}$. Examples of observed signals are given in
Fig. 1: (a) echo signal with one-multiple delay, (b) echo signal with two-multiple delay. Sometimes the multiple echo signals are registered with delay $n * \tau$, where $n=3, \ldots$. Echo signals were observed in $50 \%$ time of 1-3-h sessions. Examples of parameters of geophysical conditions are given in Table 1 . It is seen that MF propagation through the magnetosphere takes place under the following conditions: a transmitted station is located near the projection of the main ionospheric trough not far from its polar wall; premidnight hours of the winter period when the ionospheric D-layer is absent; the existence of magnetospheric substorms with $A E_{\max }=600-900 \mathrm{nT}$ and increased magnetic activity, $K_{p}=3$.

\section{Discussion}

Analysis of possible mechanisms of the phenomenon shows that the mentioned effect is neither the long-delay echoes nor round-the-world echo. Experimentally, round-the-world signals are not observed in the considered conditions. They appear usually at other times, on other frequencies and with a different timedelay $\gamma=0,138 \mathrm{~s}$, Fig. 1c. According to the experiment the echo signals are characterized by a low level of absorption and there is practically no dispersion or Doppler shift. The guiding effect is caused by the electromagnetic wave propagation into the magnetosphere near the trough and the plasmapause. These facts confirm a wave propagation along magnetic field lines through low-density plasma and may be connected with such physical phenomena as particle precipitation, wave-particle interaction etc. But an exact identification of these processes requires the development of the discussed experiments; namely, the determination in detail of the geophysical condition and the investigation of the frequency range in which the guiding effect takes place. 

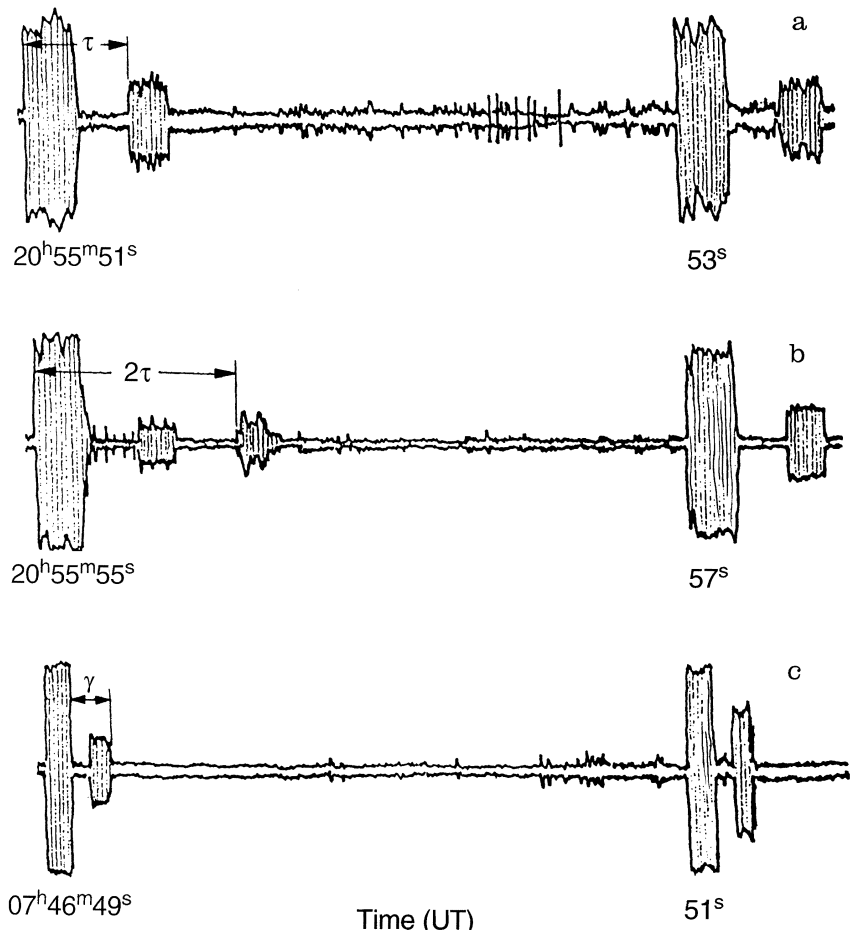

Fig. 1a-c. Registration sessions of transmitted and received signals in St. Petersburg: a,b guiding waves through the magnetosphere (there and back) with both time-delay $\tau=295 \mathrm{~ms}$ and $2 \tau=590 \mathrm{~ms} ; 16$ November $1985 ; f=1.8 \mathrm{MHz}$; c round-the-world propagation via the ionosphere with time-delay $\gamma=138 \mathrm{~ms}$; 22 December 1985; $f=14.1 \mathrm{MHz}$

\section{Modelling}

The effect of MF radio waves guiding through a magnetospheric duct (Blagoveshchensky, 1995) allows to model the conditions of the wave propagation in order to obtain observational delays of waves and to investigate the influence of plasma parameters on a group time of propagation $t_{g r}=\tau$.

The wave propagation modelling was made on the basis of the three-dimensional ray-tracing method (Maltseva and Molchanov, 1987) modified by the presence of a reflection region for the 0 -wave. This method requires some assumptions concerning the plasma model, source location and point of observation. The plasma model is based on the experimental data (Table 1), an analysis of which showed that observations took place in magneto-disturbed conditions. The critical frequency of the F2-layer was $1.5-2 \mathrm{MHz}$ near the source and $4.0-6.0 \mathrm{MHz}$ in the conjugate hemisphere. Our model includes corresponding NmF2 and altitude gradients of $N_{e}$, which are determined by a background model like the diffuse equilibrium distribution of Angerami and Thomas (1964). Latitude gradients include the plasmapause $\left(\mathrm{L}_{\mathrm{pp}}\right)$ and the main ionospheric trough, which is presented as a factor $F=1-F_{\text {atr }}$ $* \exp \left(-0.5\left(L-L_{t r}\right)^{2} / d_{t r}{ }^{2}\right)$, where $\mathrm{L}_{\mathrm{tr}}-\mathrm{L}$-shell of the centre, $d_{t r}$-width between the inner wall of the trough $\left(d_{\text {in }}\right)$ and the external wall $\left(d_{\text {out }}\right) ; F_{\text {atr }}$ describes a density
Table 1. Parameters of geophysical conditions; 1. date of observation; 2. MDT time of observation $(\mathrm{MDT}=$ Moscow decree time $=\mathrm{LT}+1)$; 3. presence of echo signals; 4. $K_{p}$ index; 5 . $F_{10.7}$ index; 6. latitude of centre of trough, obtained from array of ionosonde stations; 7. $\mathrm{f}_{0} \mathrm{~F} 2$, obtained by Murmank's ionosonde $\left(\Phi=64.5^{\circ}\right)$

\begin{tabular}{lllllll}
\hline 1 & 2 & 3 & 4 & 5 & 6 & 7 \\
\hline 22.12 .84 & $20.30-21.00$ & Yes & $2+$ & 73 & 58.4 & 3.6 \\
23.12 .84 & $20.20-21.00$ & Yes & $3+$ & 74 & 57.0 & 3.5 \\
24.12 .84 & $19.10-21.30$ & No & $1+$ & 74 & 60.5 & 3.8 \\
25.12 .84 & $19.30-21.30$ & No & 0 o & 75 & 62.6 & 4.4 \\
31.12 .84 & $20.00-21.15$ & Yes & 40 & 72 & 57.0 & 3.6 \\
3.01 .85 & $20.00-21.00$ & Yes & $3+$ & 70 & 57.0 & 4.4 \\
5.01 .85 & $20.00-21.00$ & No & $2-$ & 69 & 61.2 & 4.5 \\
6.01 .85 & $20.00-21.00$ & No & $1+$ & 70 & 60.5 & 4.3 \\
10.01 .85 & $20.00-21.00$ & Yes & 40 & 70 & 56.3 & 5.0 \\
12.01 .85 & $20.00-21.00$ & Yes & $3+$ & 71 & 57.0 & 4.0 \\
14.01 .85 & $20.00-21.00$ & Yes & $3+$ & 75 & 57.0 & 4.3 \\
27.01 .85 & $20.20-21.50$ & Yes & $7-$ & 72 & 54.2 & 5.2 \\
11.02 .85 & $21.00-21.50$ & Yes & $3+$ & 75 & 56.3 & 4.6 \\
16.11 .85 & $23.30-24.00$ & Yes & $3-$ & 81 & 56.3 & 4.8 \\
21.12 .85 & $20.00-21.00$ & No & $0+$ & 78 & 61.9 & 4.0 \\
22.12 .85 & $20.00-21.00$ & No & $1+$ & 76 & 60.5 & 3.6 \\
26.01 .86 & $21.00-22.00$ & Yes & $2-$ & 70 & 59.1 & 3.5 \\
\hline
\end{tabular}

fall in the trough and is Gaussian with 'amplitude' $A_{t r}$, centre at $h \sim h_{\max } \div 1000 \mathrm{~km}$ and a decrease in density to low altitudes and to the equatorial plane. This model provides small density gradients along the magnetic line $\left(f_{N_{e}} \sim 0.5-1 \mathrm{MHz}\right.$ in the equatorial plane). Since the plasmapause may approach $\mathrm{L}_{\mathrm{pp}}=3.3$ during a magnetic storm (Carpenter, 1963) and the difference $\mathrm{L}_{\mathrm{pp}}-\mathrm{L}_{\mathrm{tr}}$ is $0.2-0.3$ (Rycroft and Burnell, 1970), the location of $\mathrm{L}_{\mathrm{pp}}$ was chosen as 3.3-3.6. The trough is located at $\mathrm{L}_{\mathrm{tr}}=3.2$; the inner wall of the trough had size $d_{\text {in }}=0.3-0.8$, the external wall $d_{\text {out }}=0.1-0.3$. The trough depth was $1-A_{t r}$ with $A_{t r}=0.3-0.9$. The transmitter and the point of observations were located at $L_{t m}=L_{o b s}=3.2$. Waves were radiated within an angle $\delta\left(1^{\circ}-40^{\circ}\right)$ between the wave normal and the vertical.

Figure 2 shows some ray trajectories calculated in L- $\theta$ coordinates (L-shell, $\theta$-colatitude), which illustrate the possibility of radio waves passing through the magnetosphere into the conjugate hemisphere. Curve 1 is a ray path for the case $A_{t r}=0$ (no trough), which goes to large L-shells in the transmitter hemisphere quickly. Curve 2, with $A_{t r}=0.3$, illustrates the capture of waves into the channel formed by a rather shallow trough and their leaving to the large L-shell after reflection in the conjugate hemisphere. Curve 3 describes the case $\mathrm{L}_{\mathrm{pp}}=3.6, \mathrm{~L}_{\mathrm{tr}}=3.5, A_{t r}=0.9$, when the source is located on the southern wall of the trough; it can be seen that there is a leakage from the channel. Curve 4 with $\mathrm{L}_{\mathrm{pp}}=3.6, \mathrm{~L}_{\mathrm{tr}}=3.0, A_{t r}=0.9$, when the source is located on the northern wall of the trough, demonstrates both a capture and a leakage. Curve $5, \mathrm{~L}_{\mathrm{pp}}=3.6$, $\mathrm{L}_{\mathrm{tr}}=3.6, A_{t r}=0.9$, when the transmitter is situated on the southern wall but near $\mathrm{L}_{\mathrm{tr}}$, is ray trajectory with captured waves, and one can see that although the Lshell of the capture is 3.4 , a wave reaches a point with the L-shell of the transmitter. Curve 6 


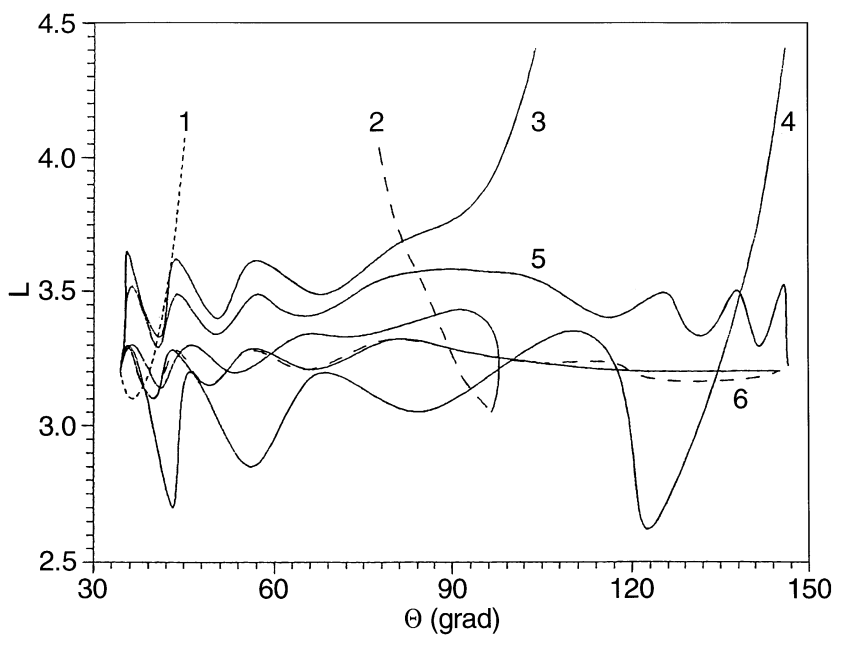

Fig. 2. Examples of ray trajectories calculated for different values of the parameters: $1-A_{t r}=0$, no trough; $2-A_{t r}=0.3$, rather shallow trough; $3-A_{t r}=0.9, \mathrm{~L}_{\mathrm{pp}}=3.6, \mathrm{~L}_{\mathrm{tr}}=3.0$; deep trough; $4-A_{t r}$ $=0.9, \mathrm{~L}_{\mathrm{pp}}=3.6, \mathrm{~L}_{\mathrm{tr}}=3.0 ;$ deep trough; $5-A_{t r}=0.9, \mathrm{~L}_{\mathrm{pp}}=3.6$, $\mathrm{L}_{\mathrm{tr}}=3.6 ;$ deep trough; $6-A_{t r}=0.9, \quad \mathrm{~L}_{\mathrm{pp}}=3.6, \quad \mathrm{~L}_{\mathrm{tr}}=\mathrm{L}_{\mathrm{tm}}=3.2$; deep trough

$\left(\mathrm{L}_{\mathrm{pp}}=3.6, \mathrm{~L}_{\mathrm{tr}}=3.2=\mathrm{L}_{\mathrm{tm}}\right)$ illustrates a capture of the wave by a channel, propagation along the magnetic field line of the transmitter and the trough, and a reflection in the magnetically conjugate region. Here the opposite trajectory is practically identical to the forward one. Thus, Fig. 2 shows that the trough is a channel in which a wave can propagate to the conjugate region (curves 3 6 ), but that channel must be sufficiently deep to prevent a leakage of those waves.

The calculated $t_{g r}$ value coincides with the experimental one only for curve 6 . It is interesting that the cases of reflection of waves from the Earth's surface in the conjugate hemisphere provide overestimated values for $t_{g r}$. In order to obtain an experimental value $t_{g r}$, waves must be reflected in the upper ionosphere of the conjugate hemisphere, although there is some uncertainty about the height of reflection because the trough ensures practically a constant delay for a wide range of trough parameters: $A_{t r}=0.4-0.9$ (the best results were obtained for $\left.A_{t r}=0.7\right)$ and $d_{i n}=0.3-0.8$. The point of reflection may be changed by the vertical gradient of $N_{e}$ in the conjugate hemisphere. One must emphasize that the return of waves to the transmitter point $\left(\mathrm{L}_{\mathrm{ob}}=\mathrm{L}_{\mathrm{tm}}\right)$ was possible for very limited locations of $\mathrm{L}_{\mathrm{tm}}, \mathrm{L}_{\mathrm{tr}}, \mathrm{L}_{\mathrm{pp}}$ : $\mathrm{L}_{\mathrm{pp}} \geq \mathrm{L}_{\mathrm{tr}}, \mathrm{L}_{\mathrm{tm}} \leq \mathrm{L}_{\mathrm{tr}}$. Multi-jumped propagation may be realized by means of certain conditions. In this case $t_{g r}$ is $n * t_{g r}$ of one jump through the magnetosphere and can exceed $1 \mathrm{~s}$.

\section{Conclusions}

The main preliminary results are as follows. (1) The particular trough may be a duct for MF waves $(f=1.8$ $\mathrm{MHz}$ ) by means of which waves may be captured, guided and reflected to a transmitter location with an observational delay $\tau=0.29$ s. (2) Magnetospheric ducting is connected with: (a) low $\mathrm{f}_{0} \mathrm{~F} 2(f \pm 0.3 \mathrm{MHz})$, (b) a low-altitude gradient of $N_{e}$ along a magnetic field line, and (c) the proximity of $\mathrm{L}_{\mathrm{tm}}, \mathrm{L}_{\mathrm{tr}}$ and $\mathrm{L}_{\mathrm{pp}}$ locations.

Acknowledgements. Topical Editor K. H. Glaßmeier thanks J. Foster for his help in evaluating this paper.

\section{References}

Angerami, J. J., and J. O. Thomas, Studies of planetary atmosphere. 1. The distribution of electrons and ions in the Earth's exosphere, J. Geophys. Res., 64, 4537-4566, 1964.

Blagoveshchensky, D. V., Diagnostics of plasmapause by effect of MF radio waves guiding, IEEE Antennas and Propagation Soc. Int. Symp., Newport Beach, California, Digest, 1, 302-305, 1995.

Calvert, W., Wave ducting in different wave modes, J. Geophys. Res. A., 100, 17491-17497, 1995.

Carpenter, D. L., Whistler evidence of a 'knee' in the magnetosphere ionization density profiles, J. Geophys. Res., 68, 16751689, 1963.

Ellis, G. R. A., and G. T. Goldstone, Sounding the magnetosphere at high frequency using ducted long-delayed echoes, J. Geophys. Res. A., 93, 7591-7594, 1988.

Maltseva, O. A., and O. A. Molchanov, VLF propagation in the magnetosphere, Nauka, Moscow, 1987.

Muldrew, D. B., Radio propagation along magnetic field-aligned sheets of ionization observed by the Alouette topside sounder, J. Geophys. Res., 68, 5355-5370, 1963.

Rycroft, M. J., and S. J. Burnell, Statistical analysis of movements of the ionospheric trough and plasmapause, J. Geophys. Res., 75, 5600-5604, 1970. 